\title{
Can carbon monoxide-poisoned victims be organ donors?
}

\author{
Noritomo Fujisaki, Atsunori Nakao*, Takaaki Osako, Takeshi Nishimura, Taihei Yamada, Keisuke Kohama, \\ Hiroyuki Sakata, Michiko Ishikawa-Aoyama and Joji Kotani
}

\begin{abstract}
The increasing demand for organ allografts to treat end-stage organ failure has driven changes in traditional donor criteria. Patients who have succumbed to carbon monoxide (CO) poisoning, a common cause of toxicological mortality, are usually rejected as organ donors. To fulfill the increasing demand, selection criteria must be expanded to include CO-poisoned donors. However, the use of allografts exposed to high CO concentrations is still under debate. Basic research and literature review data suggest that patients with brain death caused by CO poisoning should be considered appropriate organ donors. Accepting organs from CO-poisoned victims could increase the number of potential donors and lower the death rate of patients on the waiting lists. This review and reported cases may increase awareness among emergency department physicians, as well as transplant teams, that patients dying of $\mathrm{CO}$ exposure may be acceptable organ donors.
\end{abstract}

\section{Introduction}

The success of organ transplantation has led to a growing imbalance between the supply and demand of donor organs. Accordingly, the use of organs from nonconventional donors, such as those who die from carbon monoxide $(\mathrm{CO})$ poisoning, has increased. Organ procurement is based on criteria that exclude as potential donors those who have undergone prolonged cardiopulmonary resuscitation (CPR), those with certain metabolic diseases, and those with infectious diseases such as human immunodeficiency virus (HIV), hepatitis, sepsis, tuberculosis, and metastatic disease. These exclusion criteria result in a donor shortage despite an increasing number of individuals waiting for organ transplants.

$\mathrm{CO}$ is well-known in clinical medicine for its toxicity, which is due to its ability to interfere with oxygen delivery. Traditionally, CO poisoning has been considered a contraindication to organ procurement. The possibility of organ procurement from donors who died of $\mathrm{CO}$ poisoning has been discussed in the scientific literature. The possibility of permanent and significant injury to transplanted organs caused by $\mathrm{CO}$ may raise serious concerns regarding the procedure. However, a number of publications report successful organ transplantation from donors who were brain dead as a result of CO poisoning. Therefore, the belief that this poisoning automatically contraindicates donation of organs, including the heart, kidney, liver, may be unfounded.

$\mathrm{CO}$ has recently raised scientific and clinical interest, as its beneficial effects and mechanisms of action have been substantially defined in various in vitro and in vivo studies [1]. Although CO is generally known as a toxic gas, it is endogenously produced in the body and functions as an important signaling gas molecule, providing potent cytoprotective effects [2,3]. These research findings may support the idea that CO-poisoned donors should be considered appropriate for organ transplantation.

The use of organs from CO-poisoned victims for the purpose of transplantation has been poorly studied; criteria for organ donation are virtually non-existent in such cases $[4,5]$. The aim of this review is to provide an outline of previous reports of transplants from CO-poisoned donors, as well as current knowledge from CO-related clinical studies. In particular, emergency physicians must be aware that patients dying from $\mathrm{CO}$ exposure may be acceptable organ donors, because the emergency department is a critical site for organ procurement.

\footnotetext{
* Correspondence: atsunorinakao@aol.com

Department of Emergency, Disaster and Critical Care Medicine, Hyogo

College of Medicine, Nishinomiya, Hyogo, Japan
} 


\section{CO poisoning and organ injury}

While $\mathrm{CO}$ poisoning is common, its incidence is uncertain and frequently unrecognized, as the signs and symptoms are relatively nonspecific [6]. Unfortunately, no marker or constellation of signs or symptoms at presentation predict long-term outcome following $\mathrm{CO}$ poisoning $[7,8]$. Given the neurocognitive sequelae following $\mathrm{CO}$ poisoning, increased awareness and prevention of $\mathrm{CO}$ poisoning is imperative [9].

$\mathrm{CO}$ has a 200 times greater chemical affinity for hemoglobin than oxygen. The mechanisms of tissue damage due to $\mathrm{CO}$ poisoning are as follows: oxygen delivery to the tissues is reduced due to the high chemical affinity of $\mathrm{CO}$ to hemoglobin, resulting in the shift of the oxyhemoglobin dissociation curve to the left, and $\mathrm{CO}$ strongly binds to myoglobin, interfering with oxygen transportation to the mitochondria.

Various studies have demonstrated that $\mathrm{CO}$ interferes with myoglobin, P450, and other enzyme functions; causes lipid peroxidation through neutrophil activation; produces oxidative stress manifested by peroxynitrate deposition in endothelium; binds to cytochrome A3, disrupting intracellular oxygen utilization; can cause neuroexcitotoxicity; and contributes to hippocampal cellular death through apoptosis [10]. The tissues most affected are those most sensitive to oxygen deprivation, specifically those of the central nervous system and myocardium. Individual susceptibility varies and symptoms depend on degree of exposure (concentration, duration, and ventilation volume), tissue metabolic demands, concurrent anemia, and preexisting atherosclerosis.

Usually patients with $\mathrm{CO}$ poisoning also suffer from burns. Of note, admission to the hospital after a fire accident may have been exposed the patient to cyanide gases as well as CO [11].

A comparison between successful and unsuccessful transplantation cases with CO-poisoned donor organs would be quite interesting. Identifying some key characteristics of CO-poisoned donors would be beneficial for future application. However, unfortunately, most of the reports were single case reports or poorly described without detailed data, including data on $\mathrm{COHb}$ levels, $\mathrm{CO}$ poisoning time, and clinical course.

\section{Donor treatment with CO: basic research data}

$\mathrm{CO}$ potently protects against cellular injury. $\mathrm{CO}$ relaxes blood vessels and exerts anti-thrombotic effects by inhibiting platelet aggregation and derepressing fibrinolysis. In addition, $\mathrm{CO}$ reduces ischemia/reperfusion injury and inflammatory responses. CO inhibits apoptosis of endothelial and epithelial cells and reduces proliferation of smooth muscle cells, fibroblasts, and $\mathrm{T}$ lymphocytes. Thus, accumulating evidence supports the notion that $\mathrm{CO}$ treatment of transplant donors, organs, or recipients can prevent graft dysfunction due to rejection or ische$\mathrm{mia} /$ reperfusion injury.

Several studies have demonstrated that donor pretreatment with $\mathrm{CO}$ benefits graft function in animal models. In an islet allograft model, donor $\mathrm{CO}$ pretreatment blocked toll-like receptor-4 upregulation, diminishing the inflammatory response and cytokine-induced apoptosis, which protected the graft from rejection [12]. Donors who have inhaled $\mathrm{CO}$ or suffered cold ischemia with $\mathrm{CO}$ perfusion have demonstrated improved graft function, which was associated with decreased apoptosis and increased viability of endothelial cells and cardiomyocytes [13]. Induction of CO in the donor by oral administration of methylene chloride was able to prevent chronic rejection of rat renal allografts [14]. Donors treated with CORM-2 presented fewer lymphocytic infiltrates and reduced acute tubular necrosis in the graft [15]. This protection was most likely related to COinduced endothelial changes via a reduction in NADPHdependent superoxide anion production, IkB degradation, and E-selectin and ICAM-1 expression [15]. Studies on CO's mechanism of action have shown that it binds to the heme moiety of soluble guanylyl cyclase (sGC), leading to cyclic guanosine monophosphate (cGMP) activation [16].

As shown above, donor treatment with $\mathrm{CO}$ was beneficial for the survival of several types of organ grafts such as the heart, kidney, liver, and lung in animal models; we might anticipate similar efficacies of $\mathrm{CO}$ in grafts harvested from $\mathrm{CO}$-poisoned donors in humans.

\section{Clinical reports}

Several studies report the successful use of CO-poisoned victims as organ allograft donors (Table 1). Bojakowski et al. reported a single case of renal transplantation with grafts retrieved from a CO-poisoned donor. Despite prolonged warm ischemic time ( $>100$ minutes), no complications were observed in the post-transplant course, suggesting that $\mathrm{CO}$ diminished ischemia/reperfusion injury and rejection [17]. Luckraz et al. described their experience with seven patients who were transplanted using organs after fatal CO poisoning (six heart transplants and one single lung transplant). History of $\mathrm{CO}$ inhalation was obtained in all of these donors. Five of the six heart transplant patients were alive and well at the time of the study, with survival ranging from 68 to 1,879 days. One patient (a 29-year-old male) died 12 hours post-transplant due to donor organ failure. The patient who had a right single lung transplant did well initially after the transplant, but died after eight months due to Pneumocystis carinii pneumonia. All recipients who were transplanted from COpoisoned donors and ventilated for more than 36 hours survived for more than 30 days [18].

Koerner et al. reported five cardiac allografts from brain-dead, CO-poisoned donors. Donor history showed 
Table 1 List of the past report using CO-poisoned victims as organ allograft donors

\begin{tabular}{lllll}
\hline Year & Author & Journal & \# of donors & Reference \\
\hline 1989 & Karwande, et el. & J Heart Transplant & 1 heart & [19] \\
1992 & Hebert MJ, et al. & N Engl J Med & 6 kidneys & [20] \\
1992 & Shennib H et al. & J Heart Lung Transplant & 1 lung & [21] \\
1992 & Smith JA, et al. & J Heart Lung Transplant & 2 hearts & [22] \\
1993 & Iberer F, et al. & J Heart Lung Transplant & 1 heart & [23] \\
1994 & Leikin JB, et al. & Am J Emerg Med & 1 kidneys, 3 livers & [4] \\
1995 & Roberts JR et al. & Ann Emerg Med & 1 heart & [24] \\
1995 & Hantson P, et al. & J Toxicol Clin Toxicol & 1 kidney & [26] \\
1996 & Verran D, et al. & Transplantation & 2 livers & [27] \\
1997 & Koerner MM, et al. & Transplantation & 1 hearts & [28] \\
2001 & Rodrigus IE, et al. & J Heart Lung Transplant & 2 hearts, 2 kidneys, 1 pancreas \\
2001 & Bentley MJ, et al. & Ann Thorac Surg & 6 hearts, 1 lung \\
2001 & Luckraz H, et al. & Ann Thorac Surg & 1 kidney & [29] \\
2007 & Bojakowski K, et al. & Transplant Proc & 1 heart & [18] \\
2008 & Sezgin A, et al. & Transplant Proc & 1 heart & [17] \\
2008 & Martin-Suarez S, et al. & Transplant Proc & & [31] \\
\hline
\end{tabular}

$\mathrm{CO}$ intoxication in all cases. At the time of organ explantation, donor hemodynamic parameters were weak in all patients. The postoperative course was uneventful in three of the five recipients. The overall three-year survival rate in this small group was $40 \%$. Induction therapy or rescue therapy with mono/polyclonal antibodies was not necessary. Myocardial right-ventricular biopsies did not show any specific signs of CO-poisoning [27].

Verran et al. reported two successful liver transplant cases using CO-poisoned donors. There was satisfactory early function of both allografts, although marked patchy necrosis was seen on the postreperfusion biopsy (case 1) and on a 10 day postoperative biopsy (case 2). In both cases, the changes were considered to be related to damage sustained from $\mathrm{CO}$ inhalation. Both allografts soon achieved normal function and both recipients were well at the time of the study. They concluded that CO-poisoning can cause liver damage that can recover completely following liver transplantation. Shennib et al. reported a single case of successful lung transplantation using a CO-poisoned donor [21]. Sezgin et al. presented a patient who underwent a successful cardiac transplantation from a brain-dead donor who had CPR after CO intoxication. Although the donor had a history of CPR, the left ventricular ejection fraction was $55 \%$ and the echocardiographic evaluation revealed normal cardiac contractions with acceptable hemodynamic parameters. While positive inotropic support was needed in the early postoperative period, any changes related to intoxication in the endomyocardial biopsy was not observed [30].

On the other hand, contradictory evidence concerning this topic has also been published. Karwande et al. presented a case of $\mathrm{CO}$ poisoning that led to severe myocardial damage in the transplanted heart [19]. Hantson et al. reported one case of kidney transplantation from a CO-poisoned donor. In this case, the recipient was extremely unstable and the graft was rejected within a few months [25]. Rodrigus et al. presented a case of CO poisoning in a multiorgan donor that led to primary cardiac allograft failure. A biventricular assist device was used as a bridge to recovery [28].

Considering the significant risk of donor organ failure, a cautious approach is still warranted. A formal approach of invasive monitoring and active management further improves the chances of successful outcome. Predicting organ damage by blood carboxy-hemoglobin levels is quite challenging because very poor correlation has been found between blood carboxy-hemoglobin level, tissue carboxy-hemoglobin level, and degree of organ damage [32].

In general, little data regarding long-term survival are available, but individual reported cases suggest that the survival of patients transplanted with organs procured from carefully selected CO-poisoned donors may be comparable to that of patients transplanted from nonpoisoned donors. While these reports do not support the use of $\mathrm{CO}$ therapeutically during transplantation per se, they certainly do not provide any evidence that contraindicates it.

\section{Conclusion}

Currently, it is estimated that less than 1\% of all donated organs in Western Europe and the USA are procured from CO-poisoned donors [33]. Although reports of 
successful solid organ transplantation using organs from CO-poisoned donors have been published, there have also been reports of donor organ failure, resulting in early recipient death. Thus, the use of these organs for transplantation remains controversial, as little data exists from which to draw any firm conclusion. Since $\mathrm{CO}$ poisoning is common, organs procured from CO-poisoned donors could save the lives of those on donor waiting lists.

\section{Competing interests}

The authors declare that they have no competing interests.

\section{Authors' contribution}

NF and AN are responsible for writing the manuscript. TO, TN, TY, KK, HS, MIA and JK are responsible for drafting and revision. All authors read and approved the final manuscript.

Received: 15 May 2014 Accepted: 21 July 2014

Published: 31 July 2014

\section{References}

1. Otterbein LE, Bach FH, Alam J, Soares M, Tao Lu H, Wysk M, Davis RJ, Flavell RA, Choi AM: Carbon monoxide has anti-inflammatory effects involving the mitogen-activated protein kinase pathway. Nat Med 2000, 6(4):422-428.

2. Nakao A, Choi AM, Murase N: Protective effect of carbon monoxide in transplantation. J Cell Mol Med 2006, 10(3):650-671.

3. Nakao A, Toyoda Y: Application of carbon monoxide for transplantation. Curr Pharm Biotechnol 2012, 13(6):827-836.

4. Leikin JB, Heyn-Lamb R, Aks S, Erickson T, Snyder J: The toxic patient as a potential organ donor. Am J Emerg Med 1994, 12(2):151-154.

5. Wittwer T, Wahlers T: Marginal donor grafts in heart transplantation: lessons learned from 25 years of experience. Transpl Int 2008, 21(2):113-125

6. Hampson NB, Weaver LK: Carbon monoxide poisoning: a new incidence for an old disease. Undersea Hyperb Med 2007, 34(3):163-168.

7. Thomsen HK: Carbon monoxide-induced atherosclerosis in primates. An electron-microscopic study on the coronary arteries of macaca trus monkeys. Atherosclerosis 1974, 20(2):233-240.

8. Henry CR, Satran D, Lindgren B, Adkinson C, Nicholson Cl, Henry TD: Myocardial injury and long-term mortality following moderate to severe carbon monoxide poisoning. JAMA 2006, 295(4):398-402.

9. Weaver LK: Carbon monoxide poisoning. Crit Care Clin 1999, 15(2):297-317. viii.

10. Goldbaum LR, Orellano T, Dergal E: Mechanism of the toxic action of carbon monoxide. Ann Clin Lab Sci 1976, 6(4):372-376.

11. Alarie Y: Toxicity of fire smoke. Crit Rev Toxicol 2002, 32(4):259-289.

12. Goldberg A, Parolini M, Chin BY, Czismadia E, Otterbein LE, Bach FH, Wang $\mathrm{H}$ : Toll-like receptor 4 suppression leads to islet allograft survival. FASEB J 2007, 21(11):2840-2848.

13. Akamatsu Y, Haga M, Tyagi S, Yamashita K, Graca-Souza AV, Ollinger R, Czismadia E, May GA, Ifedigbo E, Otterbein LE, Bach FH, Soares MP: Heme oxygenase-1-derived carbon monoxide protects hearts from transplant associated ischemia reperfusion injury. Faseb J 2004, 18(6):771-772.

14. Martins PN, Reutzel-Selke A, Jurisch A, Denecke C, Attrot K, Pascher A, Kotsch K, Pratschke J, Neuhaus P, Volk HD, Tullius SG: Induction of carbon monoxide in donor animals prior to organ procurement reduces graft immunogenicity and inhibits chronic allograft dysfunction. Transplantation 2006, 82(7):938-944.

15. Caumartin Y, Stephen J, Deng JP, Lian D, Lan Z, Liu W, Garcia B, Jevnikar AM, Wang H, Cepinskas G, Luke PP: Carbon monoxide-releasing molecules protect against ischemia-reperfusion injury during kidney transplantation. Kidney Int 2011, 79(10):1080-1089.

16. Ramos KS, Lin H, McGrath JJ: Modulation of cyclic guanosine monophosphate levels in cultured aortic smooth muscle cells by carbon monoxide. Biochem Pharmacol 1989, 38(8):1368-1370.

17. Bojakowski K, Gaciong Z, Grochowiecki T, Szmidt J: Carbon monoxide may reduce ischemia reperfusion injury: a case report of complicated kidney transplantation from a carbon monoxide poisoned donor. Transplant Proc 2007, 39(9):2928-2929.

18. Luckraz H, Tsui SS, Parameshwar J, Wallwork J, Large SR: Improved outcome with organs from carbon monoxide poisoned donors for intrathoracic transplantation. Ann Thorac Surg 2001, 72(3):709-713.

19. Karwande SV, Hopfenbeck JA, Renlund DG, Burton NA, Gay WA Jr: An avoidable pitfall in donor selection for heart transplantation. Utah Heart Transplant Program J Heart Transplant 1989, 8(5):422-424.

20. Hebert MJ, Boucher A, Beaucage G, Girard R, Dandavino R: Transplantation of kidneys from a donor with carbon monoxide poisoning. $N$ Engl J Med 1992, 326(23):1571.

21. Shennib $H$, Adoumie R, Fraser R: Successful transplantation of a lung allograft from a carbon monoxide-poisoning victim. J Heart Lung Transplant 1992, 11(1 Pt 1):68-71.

22. Smith JA, Bergin PJ, Williams TJ, Esmore DS: Successful heart transplantation with cardiac allografts exposed to carbon monoxide poisoning. J Heart Lung Transplant 1992, 11(4 Pt 1):698-700.

23. Iberer F, Konigsrainer A, Wasler A, Petutschnigg B, Auer T, Tscheliessnigg K: Cardiac allograft harvesting after carbon monoxide poisoning. Report of a successful orthotopic heart transplantation. $J$ Heart Lung Transplant 1993, 12(3):499-500

24. Roberts JR, Bain M, Klachko MN, Seigel EG, Wason S: Successful heart transplantation from a victim of carbon monoxide poisoning. Ann Emerg Med 1995, 26(5):652-655.

25. Hantson P, Mahieu P, Hassoun A, Otte JB: Outcome following organ removal from poisoned donors in brain death status: a report of 12 cases and review of the literature. J Toxicol Clin Toxicol 1995, 33(6):709-712.

26. Verran D, Chui A, Painter D, Shun A, Dorney S, McCaughan G, Sheil R: Use of liver allografts from carbon monoxide poisoned cadaveric donors. Transplantation 1996, 62(10):1514-1515.

27. Koerner MM, Tenderich G, Minami K, Morshuis M, Mirow N, Arusoglu L, Gromzik H, Wlost S, Koerfer R: Extended donor criteria: use of cardiac allografts after carbon monoxide poisoning. Transplantation 1997, 63(9):1358-1360

28. Rodrigus IE, Conraads V, Amsel BJ, Moulijn AC: Primary cardiac allograft failure after donor carbon monoxide poisoning treated with biventricular assist device. J Heart Lung Transplant 2001, 20(12):1345-1348.

29. Bentley MJ, Mullen JC, Lopushinsky SR, Modry DL: Successful cardiac transplantation with methanol or carbon monoxide-poisoned donors. Ann Thorac Surg 2001, 71(4):1194-1197.

30. Sezgin A, Akay TH, Ozkan S, Gultekin B: Successful cardiac transplantation from donor with carbon monoxide intoxication: a case report. Transplant Proc 2008, 40(1):324-325

31. Martin-Suarez S, Mikus E, Pilato E, Bacchini M, Savini C, Grigioni F, Coccolo F, Marinelli G, Mikus PM, Arpesella G: Cardiac transplantation from a carbon monoxide intoxicated donor. Transplant Proc 2008, 40(5):1563-1565.

32. Dolan MC: Carbon monoxide poisoning. CMAJ 1985, 133(5):392-399.

33. Wood DM, Dargan Pl, Jones AL: Poisoned patients as potential organ donors: postal survey of transplant centres and intensive care units. Crit Care 2003, 7(2):147-154.

doi:10.1186/2045-9912-4-13

Cite this article as: Fujisaki et al:: Can carbon monoxide-poisoned victims be organ donors? Medical Gas Research 2014 4:13.

\section{Submit your next manuscript to BioMed Central and take full advantage of:}

- Convenient online submission

- Thorough peer review

- No space constraints or color figure charges

- Immediate publication on acceptance

- Inclusion in PubMed, CAS, Scopus and Google Scholar

- Research which is freely available for redistribution 